\title{
In the Field
}

\section{Going Virtual Together: Experiences in Adaptation and Connectivity within Academic Library Co-ops}

The four of us (Veronica Berry, Sara Clarke, Sandra Moore, and Kevin Oswald)

undertook co-ops because of the rich experiential learning opportunities that they offer.

Through our formal classroom experiences, we had learned a lot about working in libraries, the foundational concepts within Library and Information Science (LIS), and different areas of librarianship, and we were eager to know what it would feel like to work as librarians and be immersed in a library culture for a sustained period.

As lockdown began and everyone's lives turned upside down, we were incredibly grateful that Western Libraries went forward with its co-op program. However, we inevitably wondered how well the immersive experience of co-op could be translated into a virtual context and what components of the "normal" co-op experience might be lost to us; without engaging in hands-on library work within library spaces and in close proximity to our teams, would we learn as much about working in LIS and serving library users? We all jumped into the experience wholeheartedly, but, at first, we had some reservations.

What follows are our reflections on working within different functional units of Western Libraries. Kevin discusses the challenges of planning and delivering instruction online with the Teaching \& Learning team; Veronica illustrates how connection and flexibility applied to dealing with technology and collaborating with the Archives \& Special Collections and Research \& Scholarly Communication teams; Sandra 
showcases how a traditionally hands-on experience working with the Archives \& Special Collections team can be fulfilling from a distance; and Sara shows how understanding and connecting with library users is crucial while serving them remotely as a member of the User Experience (UX) and Student Engagement team. While our experiences diverged in many ways, we found that our jobs exceeded what we initially imagined would be possible within the framework of a virtual co-op. Above all, undertaking co-ops during these strange times taught us about the value of flexibility and adaptability within academic librarianship, the importance of finding ways to connect with colleagues and library users/students, and the potential to find opportunities in unexpected places.

\section{Adapting to Virtual Delivery of Instruction on the Teaching \& Learning (T\&L) Team - Kevin Oswald}

The shift to remote work and online learning continues to significantly alter the planning and delivery of library instruction sessions. Instruction historically delivered synchronously and in-person prior to the pandemic is now being delivered virtually and often in asynchronous formats. As a co-op student supporting the T\&L team during this transition, I was introduced to best practices in lesson planning and instruction delivery, but also learned to appreciate and adapt to the nuances of online learning and delivering instruction virtually.

The shift to virtual instruction has prompted experienced instructors and early career librarians to find ways to create an atmosphere together that engages students without diminishing the learning experience. My eight-month co-op was focused on experimentation, sharing experiences of success and failure, and developing best practices of virtual instruction. 
The transition to online learning is an opportunity for academic libraries to embrace modern information technology and expand their reach by creating better faculty relationships and moving away from one-shot instruction lessons. Instructors are likely to value the time savings related to librarians producing an asynchronous video to be watched by students prior to a live Q\&A discussion and an active presence on course OWL sites. A live Q\&A session will give valuable teaching time back to an instructor, and the asynchronous materials will be available for reference afterwards as well.

During my co-op, I transitioned an in-person workshop into a synchronous online session, developed a new asynchronous learning curriculum for nursing students, and co-delivered a set of virtual workshops that closely replicated in-person learning. The T\&L team is still very much in the process of figuring out how to engage, empower, and inspire students virtually. I am heartened by how passionate the group is about fulfilling this commitment, even as learning environments continue to evolve. During a relatively short timeframe, the T\&L team gained the ability to record and edit high-quality videos and integrate their material into course guides and OWL sites. They also continue to work on transitioning traditional class activities to the online environment. Importantly, the T\&L team has not viewed online learning as a temporary scenario, but rather an opportunity to streamline teaching assignments, share materials, and develop consistency. The team's teaching materials now exist as high-quality digital objects that students can use on-demand, which can also be used across different classes and disciplines. The Curriculum Librarian role is new to T\&L, and this individual is leading 
the charge to map out and bring consistency to the information literacy journey of students, which entails expanding the usability of teaching materials.

I am fortunate to have gone through this journey with the T\&L team and share in these experiences. I am confident the unique learning opportunities brought on by the pandemic will be beneficial as I develop and refine my teaching philosophy.

\section{Craving Connection \& Finding Flexibility: Not Just Components of Working with Software - Veronica Berry}

Connected is an accurate descriptor for my co-op experience. As a co-op focusing on preserving digital files through digital preservation software, it was incredibly important that I stayed connected to this software while working. However, being connected does not just apply to the internet or software; it also applies to the interactions and comradery you share as part of a team. During my co-op, I was fortunate to be part of two teams at Western Libraries: Archives \& Special Collections (ASC) and Research \& Scholarly Communication (RSC). Similar to the experience of my co-op peers, I felt supported by ASC and RSC throughout these eight months in spite of only ever interacting with these teams through email, Microsoft Teams, and Zoom. They welcomed and encouraged any questions I had about academic librarianship, provided multiple projects I could sink my teeth into, and even hosted informal lunch meetings that gave me the chance to chat with my colleagues as I would have done prior to the pandemic. These opportunities to engage with my peers resolved my fears about the potential for an isolating co-op experience and have helped me see the viability of comradery in the current virtual workplace. Though how we connect right now differs from what I expected when I began my co-op, thanks to virtual chat and video calls, it is 
still possible to engage with colleagues even during a co-op that takes place entirely from home.

When I applied for a technologically heavy co-op, I envisioned flexibility as a natural component of the position. Software can be prone to glitches or errors that make certain tasks take longer than originally planned. However, I did not imagine that being flexible in my co-op would mean dealing with software errors and failed internet connections against the backdrop of a global pandemic--a pandemic that has forced all LIS professionals, both new and experienced, to adapt in light of the shift to remote work. In my co-op, learning to adapt was necessary when I encountered internet connectivity issues in my childhood bedroom/home office and had to move to the dining room. It meant that my family tiptoed around me when I worked in the dining room, fearful of causing a disruption. Learning to adapt as part of my co-op beyond just the occasional software errors was a key lesson of this virtual experience. Prior to my co-op I considered flexibility to be a crucial skill for an LIS professional, given that technological changes require librarians to adapt. However, my virtual eight-month coop taught me how much flexibility applies to this profession beyond just technological change.

From a Distance: Adapting to Change while promoting Discovery and Access in Archives and Special Collections (ASC) - Sandra Moore

Beginning my co-op work term during a pandemic felt akin to jumping into a cold, dark, fast-moving river. The job I had originally envisioned—hands-on work with rare and unique primary source materials—suddenly needed to adapt to the shifting parameters of physical distancing and quarantine restrictions. Projects would need to take place 
online, virtually, from a distance, and the question that kept repeating itself was: would I be able to do this work remotely? As it turned out, I joined a highly collaborative, adaptable, and resilient team of people at Western Libraries, and learned to promote the discovery of primary source collections at the same time working to create access for our users-all in a virtual environment.

Being adaptable was a core theme of my experience with Western Libraries and one that I believe will serve me well in my future career. I learned that adaptability is not something you prepare for ahead of time, rather it is an attitude of flexibility, resilience, and openness to change. The unpredictable nature of the pandemic combined with the rapidly emerging responses within the library setting, challenged me to accept new experiences and undertake innovative projects that provided access to archives and special collections digitally. Very soon, I realized that archives are more than the physical collections. The expertise of the archivists themselves provides significant value to this work, from arrangement and description functions, to reference and research activities. Joining a team in this remote environment taught me a lot about the importance of working collaboratively and the effort needed to overcome barriers created by the digital environment. I learned to ask lots of questions, persevere with technological issues, and be willing to try new software when given the opportunity. Being open to ongoing professional development sessions was another way of adapting to an academic library setting, opening up new areas of knowledge that further equipped me for this aspect of LIS work.

As part of the ASC functional team, I contributed to many diverse projects that promoted discovery, such as highlighting items on social media, designing interactive 
digital exhibits, and preparing instructional videos. Assisting with reference in an online environment gave me first-hand interaction with our student, faculty, and staff user communities, which I found to be a great way to connect with people and help them get access to the resources they needed. Although working from a distance, this inspiring co-op experience taught me to be adaptable, open to new experiences, and connected me to the people, records, and work of ASC in surprising ways!

\section{A User Experience (UX) Co-op in Search of the User: Understanding Library Users' Experiences in a Pandemic - Sara Clarke}

I applied for a co-op with the UX and Student Engagement team because, like many of us in LIS, I love being immersed in libraries. I find it fascinating to learn how the design and atmosphere of different library spaces affect the people within them and their information behaviours. Additionally, connecting with and serving individuals and communities is what drew me to librarianship, so the fact that this role involved talking to library users about their experiences navigating the libraries was very exciting to me.

Of course, when I reported to my co-op position in May of 2020, the role that I was beginning necessarily looked quite different from the one that I had applied for. Western Libraries' physical locations were closed, and the library users who are the raison d'être for UX work seemed to be absent or, at least, unreachable within the context of our "new normal." As it became increasingly clear that this would be a fully remote co-op without the opportunity to set foot in the libraries or interact with library users in person, I had to adjust my understanding of library user experience and engagement with library users. 
Thankfully, the libraries' UX team is a highly collaborative one that embodies the innovative spirit associated with UX work, and by the time I joined the team they had already done much to iron out the pitfalls of working on UX virtually. Throughout my coop, we adapted hands-on UX methods to fit our remote workflows (e.g., virtual whiteboard brainstorming), worked to improve the online experience of navigating the libraries, and established new ways of connecting with users and performing user testing (e.g., the creation of the User Participation Lab). I found the iterative and creative nature of UX to be encouraging in the context of the pandemic. As an emerging LIS professional, it gave me the freedom to take creative risks in my work and "fail forward."

While working to improve the libraries' website had been part of my job description from the start, our altered context pushed me to think more deeply about the relationship between physical and virtual library spaces and how so many of the questions that we ask about physical library spaces (e.g., are they welcoming, accessible, functional, inspiring?) are equally relevant to online library spaces. If I had not been working on a remote co-op myself-and, thus, being highly reflective of my own online user experience-the impact that a well-designed library website has on the overall experience of library users may not have been as apparent to me.

In the second half of my co-op I had the opportunity to conduct accessibility testing on Zoom in order to talk to library users about their experiences interacting with the libraries' online spaces and resources. This project defied my expectations concerning the potential to connect with users virtually; the participants were very comfortable sharing their experiences and expertise in this setting. Additionally, hearing 
these students share their experiences about the challenges they encountered in navigating online spaces made it clear to me just how important creating accessible and equitable library spaces is-whether they be virtual or physical. Overall, these experiences taught me the importance of adapting to the changing needs of library users and-rather than making presumptions about these needs-finding ways to directly talk to users about their experiences in the library. The question of how library users experience the library in a pandemic turned out to be much more significant and complex than I had initially imagined. When there are barriers that dissuade or altogether prevent people from accessing library spaces or services, this is precisely the time when digging into user experience is most crucial.

\section{Conclusion}

It is important that we do not gloss over the struggles that we faced in our co-ops; in many ways, working in fully remote co-ops was not ideal and was certainly not the same experience that we would have had in face-to-face co-ops. In spite of the efforts made by our teams to stay closely connected with us, there simply is no way to recreate all of the spontaneous interactions and team dynamics that occur within in-person work situations. At times, we all experienced technological difficulties, issues with motivation within distracting home environments, and a desire to have closer connections with colleagues and library users. However, in spite of these challenges—or, to an extent, because of them-we all found that our co-ops turned out to be the rich learning opportunities that we had hoped for.

In addition to the support of our supervisors and teams, we greatly benefitted from our small community of practice. For example, the four of us kept in touch through 
Microsoft Teams chat, and we used this platform to share ideas and feedback with one another. This was especially helpful when it came to common work such as staffing the ASK a Librarian Chat service. We also had a safe and welcoming space to discuss any challenges we faced working remotely, could debrief together after professional development workshops, and discuss new resources we had discovered. Our final capstone presentation, offered virtually to all Western Libraries staff, was a collaborative effort nurtured by our shared experiences. This creative way of completing our final MLIS co-op report underscored the collective power of a community of practice to innovate, take action, and achieve common goals.

\section{Figure 1: Positive benefits of our community of practice}

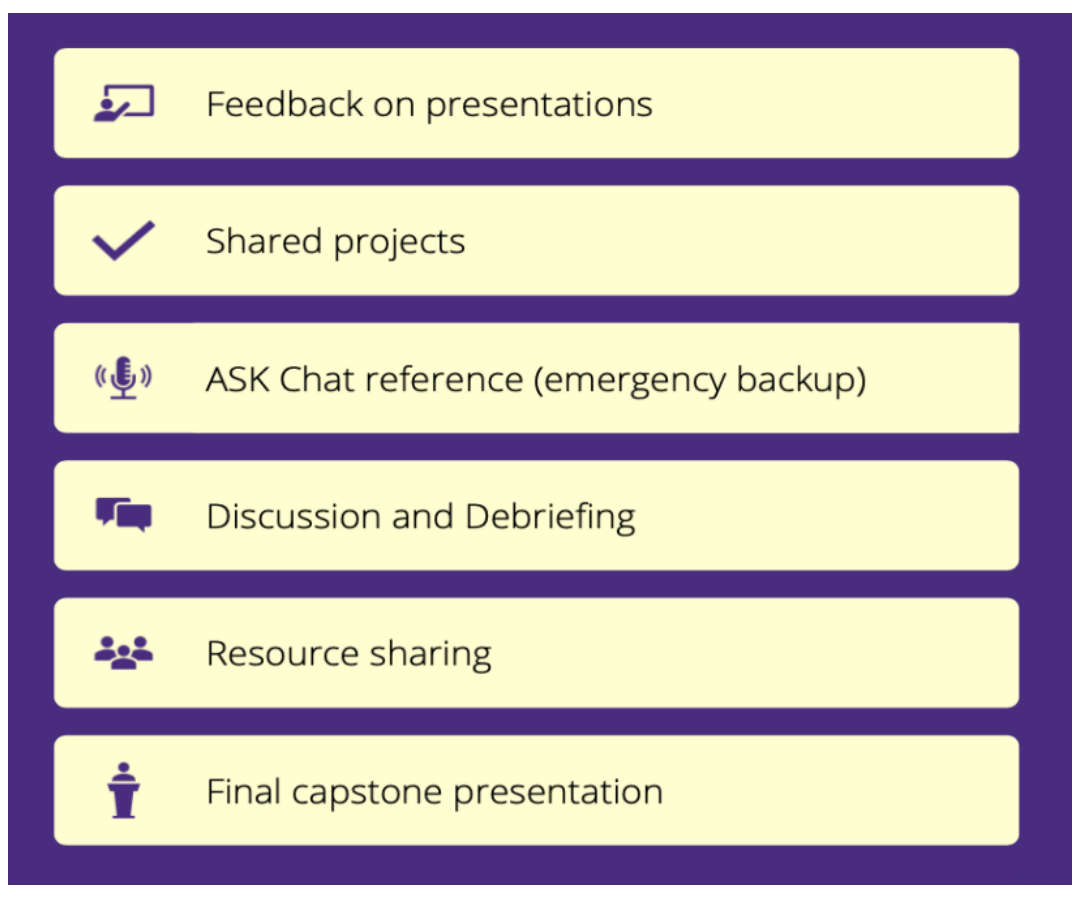

After having had some time to reflect on our experiences, we recognized that in addition to all of the specialized subject-related skills that we acquired, we also learned valuable lessons about working in LIS more generally. For instance, we all encountered a learning curve with the proliferation of acronyms in a large organization such as 
Western Libraries and became aware of the need to be mindful of defining terms in our own work. We also gained an appreciation for the value of getting involved with committees and working groups, which we found to be a great way to meet and work with people outside of our respective units. Our committee work included Western Libraries-wide collaboration on a review of research guide usage, as well as numerous diversity, equity, and inclusion initiatives. Participating in the Social Media Working Group was another opportunity that emphasized the value of uniting with colleagues from across different functional teams to promote library services and collections. Between the four of us, we engaged in Western Libraries-wide collaborations with the Research Guides Stewardship Committee, the DEI (Diversity, Equity, Inclusion) SubCommittee, the Digital Preservation and Permafrost Planning Working Group, the Social Media Working Group, and the Website Strategy Working Group. This type of crossteam work gave us an authentic experience of organizational culture and exposed us to the effectiveness of collaboration in an institutional context.

For those students considering a co-op placement, we found that introductory courses such as LIS 9003: Information Sources \& Services; LIS 9002: Information Organization, Curation \& Access; and LIS 9005: Managing and Working in Information Organizations provided us with a solid grounding in practices (e.g., conducting a reference consultation), standards (e.g., Dublin Core) and contexts, needed to be successful in our co-op placements. Although co-op settings can vary widely, if you are considering a co-op, we invite you to consider the ways in which you can apply what you have learned in your courses to your position. Additionally, depending on what your 
time, organization, and workload permits, we advise you to be open to a number of different experiences.

Figure 2: A list of courses where the content resonated with our co-op experiences

\section{Course Connections}

The formal learning environment provides significant knowledge that can be applied to the job. Here are some (but certainly not all) important connections

LIS 9003 - Information Sources \&

Services

Introduced many important concepts including research consultations, using unfamiliar and new databases and journals, lesson planning, different instruction styles, and OER

LIS 9002 - Information Organization, Curation \& Access

LIS 9201 - Classification \& Indexing

Information from a course may appear in unexpected ways. Dublin Core, often touched in cataloguing courses, is important for Digital Preservation
LIS 9005 - Managing and Working in Information Organizations

Introduction to, and exploration of the differences, between different organizational models - particularly understanding the shift from liaison to functional/hybrid models of organization

LIS 9630 - Academic

Libraries

Expanding on the discussion of functional vs. liaison structure, consideration of collections strategies and the serials crisis, scholarly communication and open access, and efforts to decolonize the workspace.

To conclude, although working remotely was unexpected and at times challenging, we think that the ingredients for a rich co-op experience are very similar between virtual and in-person co-ops. The opportunity to learn both general and specialized skills, to build professional relationships, and gain an awareness of the trends and current issues at the forefront of the LIS world are invaluable assets to carry forward. Above all, this experience proved that academic librarianship-while requiring adaptability and openness to change-is a richly rewarding, dynamic field, and worth pursuing as both a co-op and future career. 
Figure 3: A list of characteristics of a rich co-op experience as they relate to: developing professional awareness; learning and skill building; relationship building

\section{Ingredients for a rich co-op experience...}

Developing professional awareness

- Organizational awareness

- Awareness of trends within a subject area

- Learning about hiring processes
Learning and skill building

- Developing general and specific skills

- Research projects

- Leadership opportunities

- Opportunities to take risks and experiment

- Receiving feedback

- PD opportunities
Relationship building

- Collaborating with team members

- Collaborating across units; committee work

- Mentorship

- Internal and external networking

- Community of practice

Veronica Berry, Sara Clarke, Sandra Moore, and Kevin Oswald

Berry, V., Clarke, S., Moore, S., \& Oswald, K. (2021). Going virtual together: Experience in adaptation and connectivity with academic library co-ops. Emerging Library \& Information Perspectives, 4, 193-205. https:/doi.org/10.5206/elip.v4i1.13498 